\title{
The vicious cycle towards violence: focus on the negative feedback mechanisms of brain serotonin neurotransmission
}

\section{Sietse F. de Boer*, Doretta Caramaschi, Deepa Natarajan and Jaap M. Koolhaas}

Department of Behavioral Physiology, University of Groningen, Haren, The Netherlands

\section{Edited by:}

Carmen Sandi, Ecole Polytechnique

Fédérale de Lausanne, Switzerland

\section{Reviewed by:}

Jozsef Haller, Institute of Experimental

Medicine, Hungary

Carmen Sandi, Ecole Polytechnique

Fédérale de Lausanne, Switzerland

*Correspondence:

Sietse F. de Boer, Department of

Behavioral Physiology, University of

Groningen, P.O.Box 14, 9750 AA Haren,

The Netherlands.

e-mail:s.f.de.boer@rug.nl
Violence can be defined as a form of escalated aggressive behavior that is expressed out of context and out of inhibitory control, and apparently has lost its adaptive function in social communication. Little is known about the social and environmental factors as well as the underlying neurobiological mechanisms involved in the shift of normal adaptive aggression into violence. In an effort to model the harmful acts of aggression and violence in humans, we recently (re)developed an animal model that is focused on engendering uncontrolled forms of maladaptive aggressive behavior in laboratory-bred feral rats and mice. We show that certain (8-12\%) constitutionally aggressive individuals gradually develop, over the course of repetitive exposures to victorious social conflicts, escalated (short-latency, high-frequency and ferocious attacks), persistent (lack of attack inhibition by defeat/submission signals and perseverance of the aggressive attack-biting bout), indiscriminating (attacking female and anesthetized male intruders) and injurious (enhanced vulnerable-body region attacks and inflicted wounding) forms of offensive aggression. Based on the neurobiological results obtained using this model, a revised view is presented on the key role of central serotonergic (auto)regulatory mechanisms in this transition of normal aggression into violence.

Keywords: aggression, violence, rodents, serotonin, $5-\mathrm{HT}_{1 \mathrm{~A}}$ receptor

\section{INTRODUCTION}

The human capacity for unchecked aggressiveness and violence inflicts an awful and costly burden on society. Unfortunately, the current intervention strategies and treatment options for curbing these problematic behavioral expressions are largely inadequate. Hence, a more fundamental knowledge about the social and neurobiological determinants of aggression is desperately needed. In particular, the interaction between environmental factors and the neurochemical substrates that specifically underlies the shift towards escalated and maladaptive forms of aggressive behavior (e.g., violence) need to be unraveled. Experimental laboratory models of aggression in rodents and other animal species are indispensable to obtain this goal. However, most animal studies of aggression have traditionally been concerned with the ultimate and proximate mechanisms of normal adaptive aggressive behavior, while clinically the focus is predominantly on violent individuals and excessive or inappropriate forms of human aggression. Besides several ethical, funding and translational constraints, the lack of biologically relevant and valid animal models of these pathological forms of aggressive behavior is one important reason for the gap in our knowledge about the neurobiological roots and mechanisms of violence in humans. Therefore, new experimental models in preclinical research are now being developed that focus more on provoking escalated and uncontrolled forms of aggressive behavior in order to approximate the behavior of direct concern in public health and criminal justice (Miczek et al., 2004, 2007; Haller and Kruk, 2006; Nelson and Trainor 2007).

\section{ANIMAL MODELS}

One major methodological obstacle for developing valid animal models of violence is the fact that most laboratory animal studies of aggression are conducted in rodent strains that are very placid and docile. In virtually all laboratory mouse and rat species, the aggressive behavioral traits (including the underlying genetic components) have been dramatically compromised due to selection and inbreeding in the course of the century-long domestication process. Consequently, to obtain appreciable levels of offensive aggression in these timid and predominantly serene laboratory strains, several procedural manipulations have been employed to enhance their general tendency to display offensive aggressiveness. Obviously, some of these procedures have been adopted with the intent to mimic the conditions under which violent behavior in humans occur. Generally, these procedures can be categorized into manipulations at the (A) behavioral/environmental, (B) neurophysiological (C) neuropharmacological and (D) genetic level. An overview of these various procedural manipulations/paradigms that heighten aggression, and its similarity to the symptomatology, etiology, neurobiology and pharmacology of human violent behavior according to the general validity criteria of animal models (face, construct and predictive), are listed in Table $\mathbf{1}$ and the reader is referred to another paper in this special issue (Natarajan et al., in review) for a brief description of these various animal models.

Clearly, several of these models have a reasonable constructvalidity with the violence-provoking conditions and mechanisms in humans. However, while the listed experimentally-heightened forms of aggressive behavior may to some extent resemble more intense forms when compared to the already low species-typical rates of 
Table 1 | Procedural manipulations to induce increased levels or pathological forms of aggressive behavior in experimental animals (rats, mice and hamsters).

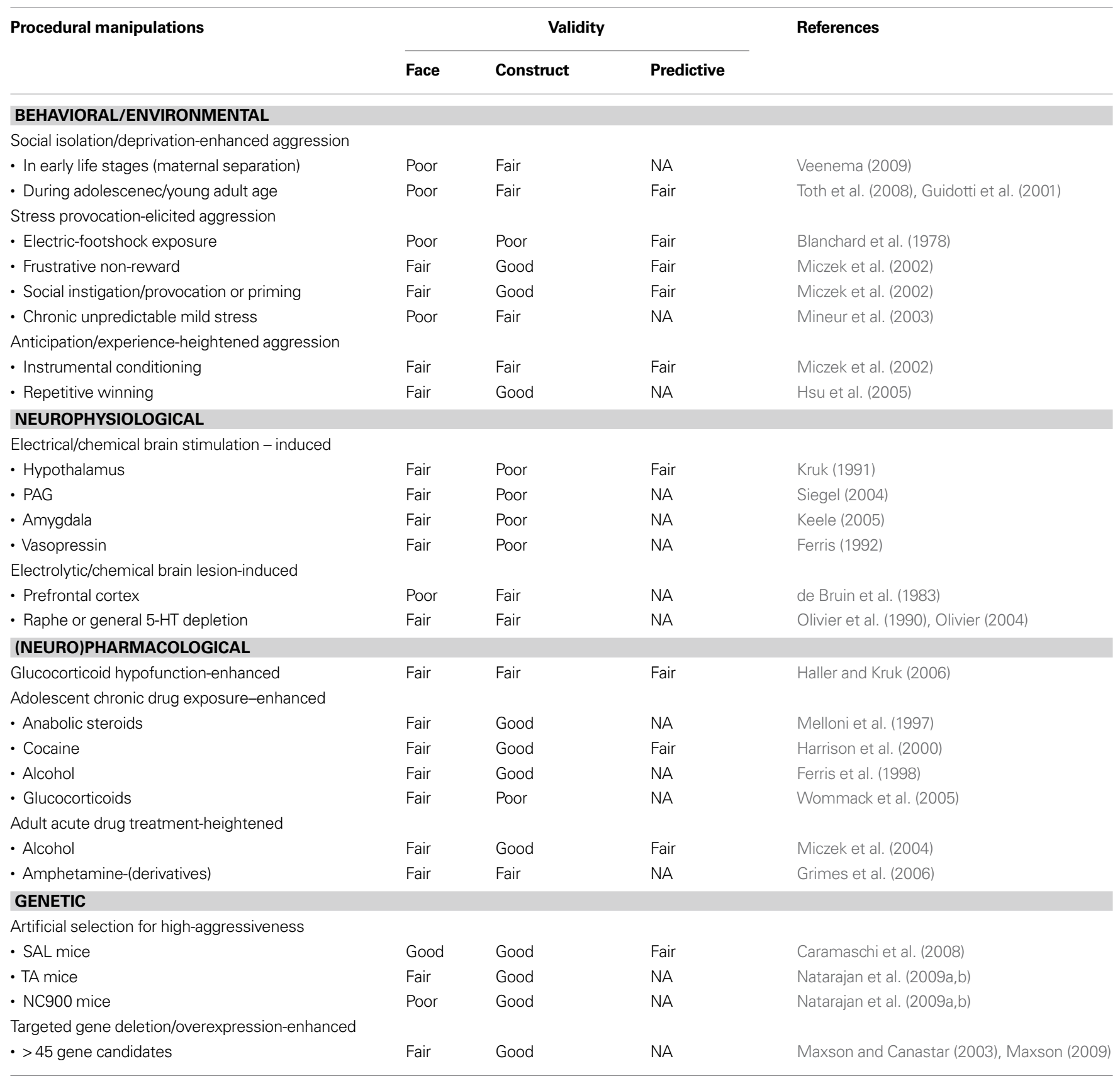

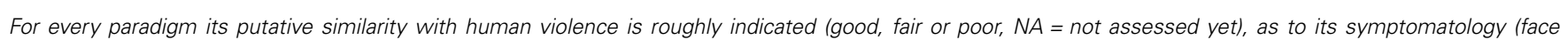

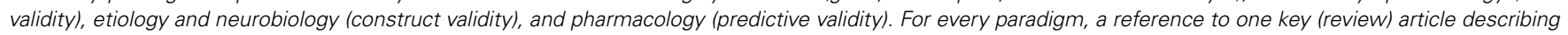
the employed methodology is given.

aggression in these laboratory animals, they mostly still fall into the normative range when compared to the patterns and levels of their wild ancestors. Indeed, much higher levels and broader-ranges of spontaneous and normal adaptive resident-intruder offensive aggression are encountered in feral or semi-natural populations of rats and mice as compared to their laboratory-bred conspecifics (de Boer et al., 2003). Therefore, an increase in the intensity of aggression as reflected by shorter attack latencies and/or enhanced frequency and duration of attacks is only one quantitative aspect of an individual's aggressive behavioral tendency and does not automatically reflect abnormal forms of aggression that are characteristic of violence. More productive and clinically relevant animal models of pathological expression of aggression should demonstrate intense and injurious aggression that exceeds normal species-typical levels and patterns (Miczek et al., 2004; Haller and Kruk, 2006; Nelson and Trainor, 2007). In other words, forms of aggressive behavior 
that is not subject to inhibitory control anymore and has lost their adaptive function in social communication. This out of control, out of content and out of context aggressive behavior is expressed in:

1. The disappearance of the normal investigatory and threatening sequence of acts and postures, and immediately engage in the ultimate consummatory phase of aggression i.e., the physical attack-bite bout (reflected in decreased attack-bite latencies and high attack/threat ratios).

2. Persistence in the aggressive attack-biting mode even though the intruder displays submissive supine and crouching/defeat postures that normally terminates the aggressive attack bout in the resident (quantifiable by disorganized temporal and sequential structure of social and aggressive behavior or perseverance of the aggressive attack-biting bout).

3. Orienting the attack-bites toward vulnerable-body regions (head and ventral surface) of the opponents resulting in severe wounding and eventually death of the intruder if not stopped by the experimenter (indicated by increased vulnerable attack ratios and inflicted wounds).

4. Losing the ability to discriminate context and/or the type of opponent (resulting in attacking dominant males, females or even anesthetized/dead conspecifics). Inclusion of these core behavioral abnormality criteria for deviant aggressiveness in rodent aggression models will certainly add to the validity of a "violence" model and expansion of our much needed knowledge about the neurobiology of pathological and violent forms of human aggression.

\section{FROM AGGRESSION TO VIOLENCE}

Recent experiments in our lab using feral (wild-derived) rats and mice have shown that the above described violent characteristics can be engendered in certain medium to high-aggressive wild-type rats (approximately $8-12 \%$ of the animals) upon repeatedly permitting them to dominate intruder conspecifics during resident-intruder contests. Enhanced levels of offensive aggression and an increased probability of winning an aggressive encounter following previous victories (the so-called "trained fighter" or "winner" effect) was originally described by Ginsberg and Allee (1942), and since then has been demonstrated frequently in a wide variety of animal species (see Hsu et al., 2005, for review). Furthermore, this effect is reported to be most pronounced in the more aggressive individuals (Oyegbile and Marler, 2006). Clearly, some of our constitutionally aggressive male wild-type rats gradually develop, over the course of 10-25 repetitive exposures of victorious social conflicts escalated (short-latency, high-frequency and-intensity attacks), persistent (lack of attack inhibition by defeat/ submission signals), indiscriminating (attacking female and anesthetized male intruders) and injurious (enhanced vulnerable-body region attacks) forms of offensive aggression (Figure 1).

Similarly, male wild-derived house mice that were artificially selected for short-attack latencies (i.e., high-aggressive SAL mice) show virtually all of the above-mentioned signs of violent aggressive behavior already after 3-5 repeated winning experiences (Haller et al., 2006; Caramaschi et al., 2008; Natarajan et al., 2009a,b). Compared to non-aggressive LAL or low/normal-aggressive aLAL males, SAL mice display very short-latency and high-frequency of biting attacks with approximately half of those aimed at vulnerable-body regions (neck, head and belly). Furthermore, 80-90\% of the fighting-experienced SAL males started to attack anaesthetized male intruders as well as (oestrus) females (Figure 2).

Thus, upon positive reinforcing or "pleasurable" victorious social experiences, these constitutionally high-aggressive rats and mice are very prone to show a breakdown of the aggressive behavioral inhibition mechanisms, and transform their initial functional adaptive aggressive behavior into a more violent and pathological form.

\section{SEROTONIN}

Obviously, this animal model affords us the opportunity to identify the neural plastic changes in the neurochemical "aggression" control systems that are hypothesized to underlie such a transformation. To date, we have focused in particular on the (auto)-regulatory components of brain serotonin (5-HT) neurotransmission. More than any other neurochemical system, this evolutionary ancient and very well conserved neurotransmitter system is generally considered the primary molecular orchestrator of aggression in a wide variety of animal species (Kravitz and Huber 2003; Miczek et al., 2004; Summers et al., 2005). However, the nature of this linkage is complex and it has proven difficult to unravel the precise role of this amine in the predisposition for and execution of aggressive behavior in both its normal and pathological forms. The big dogma that 5-HT generally inhibits aggression is obsolete now and the much-favored 5-HT deficiency hypothesis of aggression has to be revised. Ongoing research from our and other research groups on the functional status of the 5-HT system before, during and after the execution of normal adaptive and abnormal pathological forms of aggression has led to the following view: display of normal adaptive aggressive behavior aimed at territorial control, social dominance and coherence is positively related to 5-HT neuronal (re)activity, whereas an inverse relationship develops between tonic, trait-like 5-HT activity and pathological forms of aggression (e.g., violence). For example, in our wild-type rats, a clear positive correlation was found between the level of adaptive aggressiveness and basal CSF concentrations of 5-HT and/or its metabolite 5-HIAA (van der Vegt et al., 2003a). Moreover, local tissue as well as microdialysate levels of 5-HT and 5-HIAA in the frontal cortex did not differ significantly between high- and low-aggressive animals, although there was a slight tendency for lower levels in high-aggressive animals (de Boer et al., 2003; Figure 3). This negative correlation between aggression and frontal cortical 5-HT levels became highly significant upon inclusion of samples from the abnormal and excessively aggressive trained fighter animals (Figure 3).

Apparently, tonic brain 5-HT activity decreases as a consequence of acquiring repeated victorious experiences and adopting unchecked forms of aggression. A similar observation was made recently in our feral, artificially-selected high-aggressive mice: Only after repeated resident-intruder fighting experience, serotonin levels in the prefrontal cortex were found to be significantly lower in violent SAL mice (Figure 4; Caramaschi et al., 2008).

Moreover, these data are consistent with microdialysis studies showing lower prefrontal 5-HT values in aggressive individuals only after the fighting had been initiated and when it was terminated (Van Erp and Miczek, 2000) or merely anticipating aggression in individuals who are extensively trained/primed for aggression (Ferrari et al., 2003). Furthermore, these findings accommodate and bridge the aggressive behavior stimulatory role of 5-HT described 


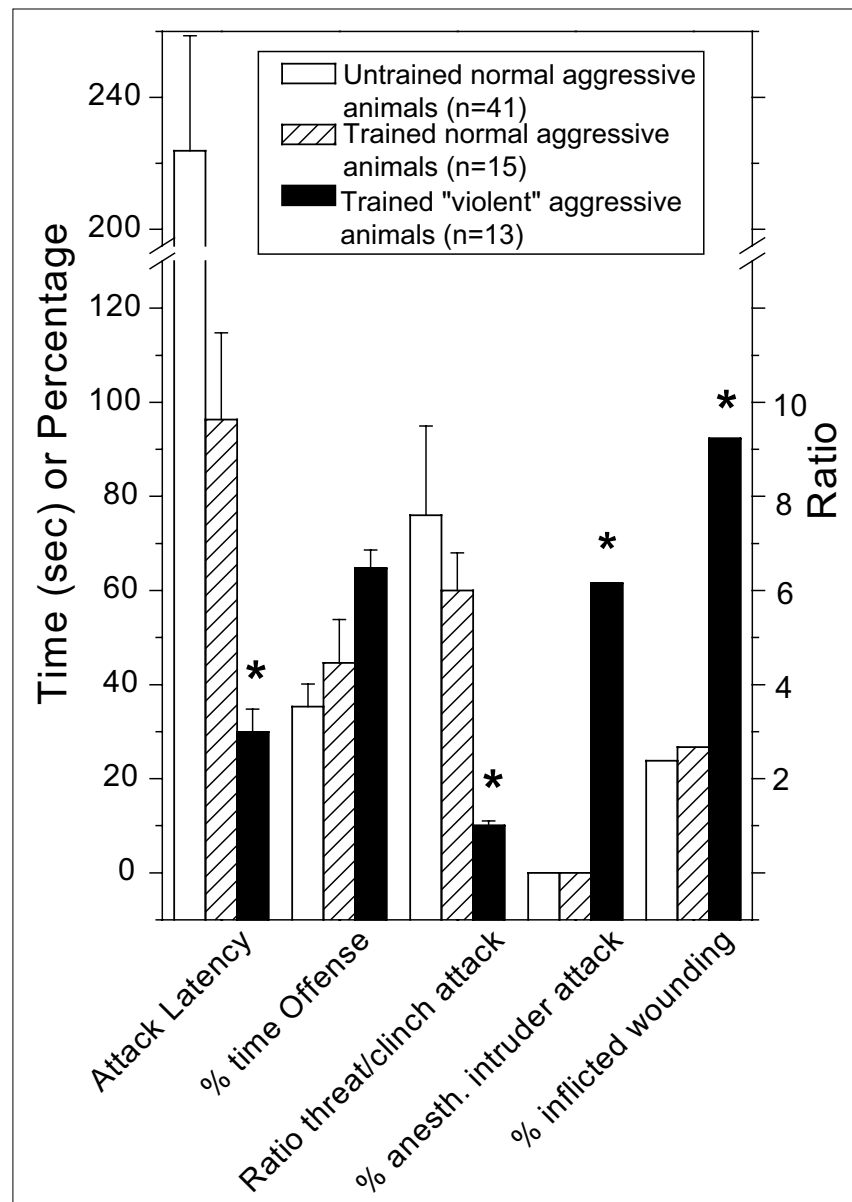

FIGURE 1 | Normal and 'violent' aggressive behavioral characteristics in resident wild-derived rats after none (naïve, untrained group) and repetitive (experienced, trained groups) victorious experiences. See de Boer and Koolhaas, 2005 for methodological details of the rat resident-intruder offensive aggression test. ${ }^{*}$ indicates significantly ( $p<0.05$; student $t$-test) different from untrained and trained normal-aggressive groups.

for several invertebrate species (for review see Kravitz and Huber, 2003) and the putative inhibitory role of 5-HT in rodent and primate species. Indeed, a critical evaluation of the csf 5-HIAA data in aggressive humans and monkeys revealed that the serotonergic deficiency appears to be most readily detected in well-circumscribed groups of individuals who had engaged in impulsive and violent forms of aggressive behavior rather than in individuals with more instrumental (functional) forms of aggression (Coccaro, 1989; Raleigh et al., 1991; Mehlman et al., 1994; Tuinier et al., 1995).

\section{5-HT AUTORECEPTORS}

Profound functional changes in the key autoregulatory sites that importantly control firing and 5-HT release of the serotonergic neurons, i.e., presynaptic 5- $\mathrm{HT}_{1 \mathrm{~A}}$ and $5-\mathrm{HT}_{1 \mathrm{~B}}$ autoreceptors and serotonergic reuptake transporters (5-HTT), are hypothesized to causally underlie this transition of normal adaptive aggressive behavior into abnormal excessive forms that cause harm and injury. Previously, we and others clearly showed that acute treatment with 5- $\mathrm{HT}_{1 \mathrm{~A}}$ and 5- $\mathrm{HT}_{1 \mathrm{~B}}$ receptor agonists potently and selectively

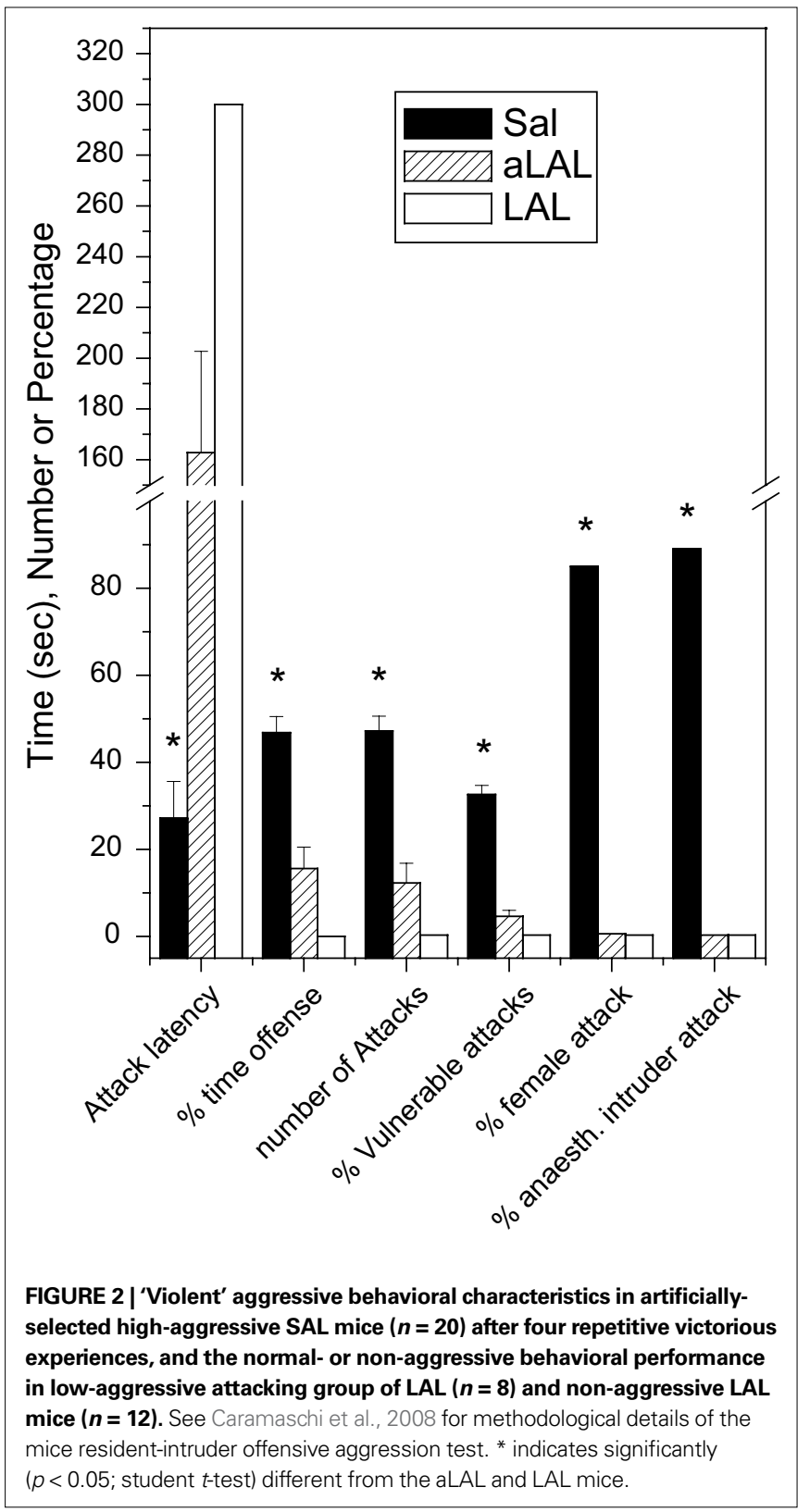

suppressed aggressive behaviour (see Miczek et al., 2004 and Olivier and van Oorschot, 2005 for reviews). Moreover, we showed that these anti-aggressive effects are largely expressed via their action on the inhibitory somatodendritic and terminal autoreceptors, presumably attenuating intruder-activated 5-HT neurotransmission (see de Boer and Koolhaas, 2005 for review). This strongly indicates that the actual display of aggressive behavior, or at least the intent thereof, is associated with (short-lasting) increased 5-HT neurotransmission, a paradoxical view but supported by increased molecular neuronal activation markers (immediate-early gene expression) in 5-HT-positive raphe neurons after performance of aggressive behavior (van der Vegt et al., 2003b; Veening et al., 2005). This view agrees well with the general hypothesis that activation of the 5-HT system is most strongly related to general motor activity (Jacobs and Fornal, 1999). 


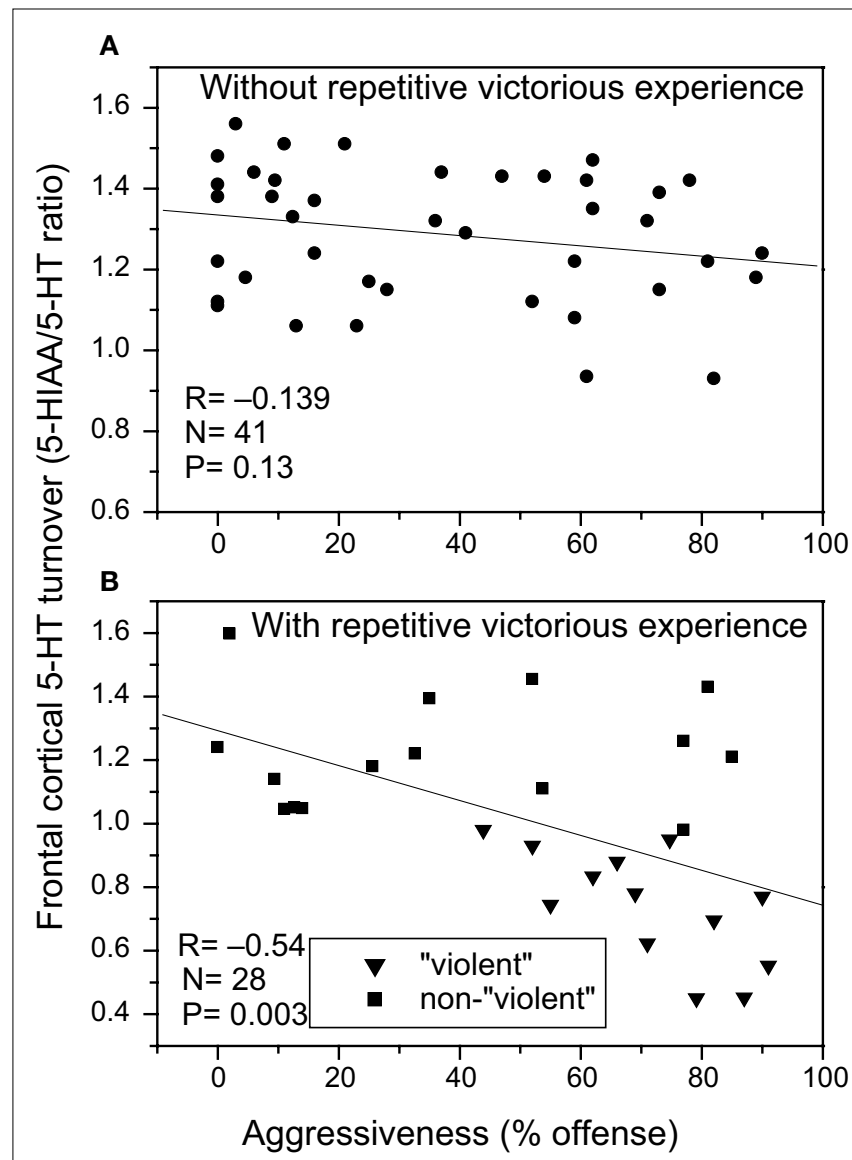

FIGURE 3 | Relationship between the individual level of aggressiveness (measured as \% time spent on offensive aggressive behaviors during a $10 \mathrm{~min}$ resident-intruder conflict test) and frontal cortical serotonin turnover (measured as the ratio between tissue concentration 5-HIAA and 5-HT) in (A) untrained residents and (B) trained fighter rats that either show abnormal and/or violent aggressive characteristics (filled triangles) or normal forms of aggressiveness (filled squares). Note that 5 -HT turnover deficiency occurs in only those individuals that developed excessive and abnormal forms of aggressiveness upon repeatedly winning fights. Data partly taken from de Boer and Koolhaas (2005), see Caramaschi et al. (2007) for technical details of prefrontal tissue $5-\mathrm{HT} / 5-\mathrm{HIAA}$ measurements.

More importantly, we found that the broad individual differences in offensive aggression in our wild-type animals are associated with pronounced functional, but not structural, differences in 5- $\mathrm{HT}_{1 \mathrm{~A}}$ and 5- $\mathrm{HT}_{1 \mathrm{~B}}$ properties: compared to low-aggressive animals, high-aggressive animals are characterized by enhanced somatodendritic 5- $\mathrm{HT}_{1 \mathrm{~A}}$ and terminal 5- $\mathrm{HT}_{1 \mathrm{~B}}$ autoreceptor activity (de Boer et al., 2001; van der Vegt et al., 2001; Caramaschi et al., 2007).

\section{REFERENCES}

Blanchard, R. J., Blanchard, D. C., and Takahashi, L. K. (1978). Pain and aggression in the rat. Behav. Biol. 23, 291-305.

Caramaschi,D.,deBoer,S.F., and Koolhaas, J. M. (2007). Differential role of the 5-HT1A receptor in aggressive and non-aggressive mice: an across-strain comparison. Physiol. Behav. 90, 590-601.

Caramaschi, D., de Boer, S. F., de Vries, H., and Koolhaas, J. M. (2008). Development of violence in mice through repeated victory along with changes in prefrontal cortex neurochemistry. Behav. Brain Res. 3;189, 263-272.

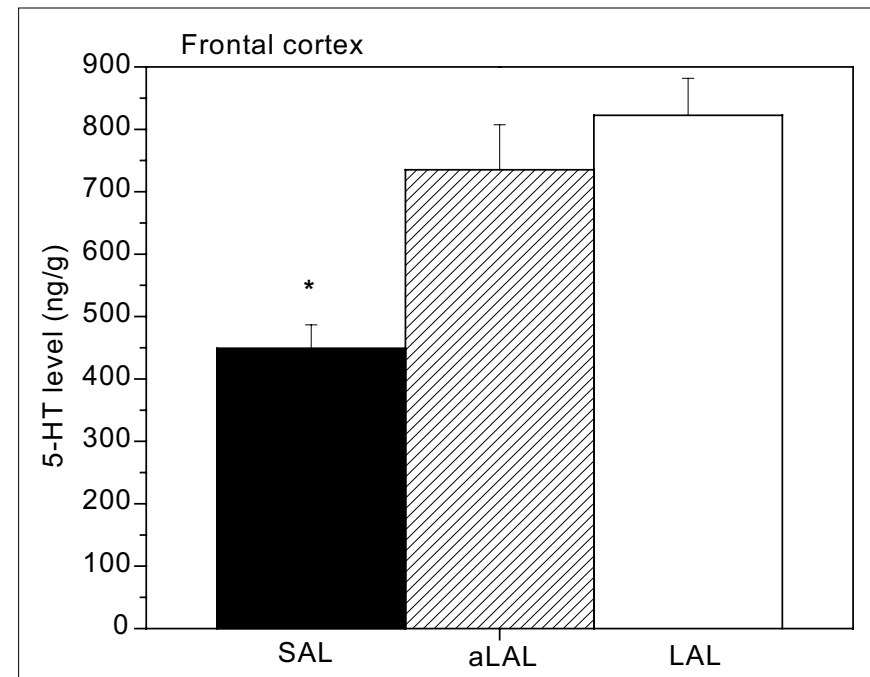

FIGURE 4 | Prefrontal cortex tissue levels of 5-HT in trained and excessively ('violent') aggressive SAL mice $(n=12)$, normal lowaggressive $\operatorname{LAL}(\boldsymbol{n}=\mathbf{8})$ and non-aggressive LAL mice $(\boldsymbol{n}=11)$. * indicates significant different ( $p<0.05$; student $t$-test) from the (a) LAL mice.

Furthermore to signify the causality of this correlation, 5-HT1A autoreceptor sensitivity increased or decreased upon enhancing (by repeated victory experiences) or attenuating (by repeated defeat experiences) aggressiveness, respectively.

Currently, we scrutinize the various cellular and molecular mechanisms (i.e., receptor internalization, $\mathrm{G}_{\mathrm{i}} / \mathrm{G}_{\mathrm{o}}$-effector protein coupling, GIRK-channel activation/expression, TREK-1 potassium channel activation/expression) that importantly regulate this inhibitory autoreceptor function to ascertain the main cause of the detected 5-HT ${ }_{1 \mathrm{~A}}$ autoreceptor supersensitivity.

\section{CONCLUDING REMARKS}

Our results support the need to delineate aggression as a highly functional form of social communication from violence. Display of normal adaptive aggressive behavior aimed at territorial control, social dominance and coherence is positively related to 5 -HT neuronal (re)activity, whereas an inverse relationship develops between tonic, trait-like 5-HT activity and pathological forms of aggression. Based on our findings we hypothesize that the enhanced inhibitory autoreceptor function is a normal compensatory adaptive response to the more reactive state of the brain 5-HT system in high-aggressive animals. However, an excessive activation or perhaps overshooting of this normal autoreceptor brake function may be a causative link in the cascade of neurochemical events leading to the 5-HT hypofunction characterizing violence as the pathological form of aggression.

Coccaro, E. F. (1989). Central serotonin and impulsive aggression. Br. J. Psychiatry Suppl. 52-62.

de Boer, S. F., and Koolhaas, J. M. (2005). 5-HT1A and 5-HT1B receptor agonists and aggression: A pharmacological challenge of the serotonin deficiency hypothesis. Eur. J. Pharmacol. 526, 125-139. de Boer, S. F., van der Vegt, B. J., and Koolhaas,J.M.(2001).Hypersensitivity of 5-HT1A and 5-HT1B autoreceptors as causal neuromechanism underlying high trait aggressiveness. Abstr. - Soc. Neurosci. 89, 7.

de Boer, S. F., van der Vegt, B. J., and Koolhaas, J. M. (2003). Individual variation in aggression of feral rodent 
strains: a standard for the genetics of aggression and violence? Behav. Genet. 33, 485-501.

de Bruin, J. P., van Oyen, H. G., and Van de Poll, N. (1983). Behavioural changes following lesions of the orbital prefrontal cortex in male rats. Behav. Brain. Res. 10, 209-232.

Ferrari, P. F., Van Erp, A. M. M., Tornatzky, W., and Miczek, K.A. (2003).Accumbal dopamine and serotonin in anticipation of the next aggressive episode in rats. Eur. J. Neurosci., 17, 371-378.

Ferris, C. F. (1992). Role of vasopressin in aggressive and dominant/subordinate behaviors. Ann. N. Y. Acad. Sci. 652, 212-226.

Ferris, C. F., Stiegman, K., and King, J. A. (1998). Voluntary alcohol consumption in male adolescent hamsters increases testosterone and aggression. Physiol. Behav. 63, 739-744.

Ginsberg, B. E., and Allee, W. C. (1942). Some effects of conditioning on social dominance and subordination in inbred strains of mice. Physiol. Zool. 15, 485-506.

Grimes, J. M., Ricci, L, Rasakham, K., and Melloni, R. H. (2006). Drugs of abuse and aggression. In Biology of Aggression, R. J. Nelson, ed. (Oxford, Oxford University Press), pp. 371-424.

Guidotti, A., Dong, E, Matsumoto, K., Pinna, G, Rasmusson, A. M., and Costa, E. (2001). The socially-isolated mouse: a model to study the putative role of allopregnanolone and 5adihydroprogesterone in psychiatric disorders. Brain Res. Rev. 37, 110-115.

Haller, J., and Kruk, M. R. (2006). Normal and abnormal aggression: human disorders and novel laboratory models. Neurosci. Biobehav. Rev. 30, 292-303.

Haller, J., Toth, M., Halasz, J, and de Boer, S. F. (2006). Patterns of violent aggression-induced brain c-fos expression in male mice selected for aggressiveness. Physiol. Behav. 88, 173-182.

Harrison, R. J., Connor, D. F., Nowak, C., and Melloni, R. H. (2000). Chronic low-dose cocaine treatment during adolescence facilitates aggression in hamsters. Physiol. Behav. 69, 555-562.

Hsu, Y., Earley, R. L., and Wolf, L. L. (2005). Modulation of aggressive behaviour by fighting experience: mechanisms and contest outcomes. Biol. Rev. 80, $1-42$.

Jacobs,B.L.,andFornal,C.A.(1999).Activity of serotonergic neurons in behaving animals. Neuropsychopharmacology 21, 9S-15S.

Keele, N. B. (2005). The role of serotonin in impulsive and aggressive behaviors associated with epilepsie-like neuronal hyperexcitability in the amygdale. Epilepsy Behav. 9, 557-563.

Kravitz, E. A., and Huber, R. (2003). Aggression in invertebrates. Curr. Opin. Neurobiol. 13, 736-743.

Kruk, M. R. (1991). Ethology and pharmacology of hypothalamic aggression in the rat. Neurosci. Biobehav. Rev. 15, 527-538.

Maxson, S. C. (2009). The genetics of offensive aggression in mice. In Handbook of Behavior Genetics, Y.K. Kim, ed. (Springer, New York), pp. 301-316.

Maxson, S. C., and Canastar, A. (2003). Conceptual and methodological issues in the genetics of mouse agonistic behavior. Horm. Behav. 44, 258-262.

Mehlman, P. T., Higley, J. D., Faucher, I, Lilly, A. A., Taub, D. M., Vickers, J., Suomi, S. J., and Linnoila, M. (1994). Am. J. Psychiatry 151, 1485-1491.

Melloni, R. H., Conner, D. F., Xuan Hang, P. T., Harrison, R. J., and Ferris C. G. (1997). Aanabolic-androgenic steroid exposure during adolescence and aggressive behavior in golden hamsters. Physiol. Behav. 61, 359-364.

Miczek, K. A., de Almeida, R. M., Kravitz, E.A., Rissman, E. F., de Boer, S. F., and Raine, A. (2007). Neurobiology of escalated aggression and violence. $J$. Neurosci. 27, 11803-11806.

Miczek, K.A., Faccidomo, S., De Almeida, R. M., Bannai, M., Fish, E. W., and Debold, J. F. (2004). Escalated aggressive behavior: new pharmacotherapeutic approaches and opportunities. Ann. N. Y. Acad. Sci. 1036, 336-355.

Miczek, K. A., Fish, E. W., De Bold, J. F., and DE Almeida, R. M. (2002). Social and neural determinants of aggressive behavior: pharmacotherapeutic targets at serotonin, dopamine and gamma-aminobutyric acid systems. Psychopharmacology (Berl.) 163, 434-458.

Mineur, Y. S., Prasol, D. J., Belzung, C., and Crusio, W. E. (2003). Agonistic behavior and unpredictable chronic mild stress in mice. Behav. Genet. 33, 513-519.

Natarajan, D., de Vries, H., de Boer, S. F., and Koolhaas, J. M. (2009a). Violent phenotype in SAL mice is inflexible and fixed in adulthood. Aggress. Behav. 35, 430-436.
Natarajan, D., de Vries H., Saaltink, D. J., de Boer, S. F., and Koolhaas, J. M. (2009b). Delineation of violence from functional aggression in mice: an ethological approach. Behav. Genet. 39, 73-90.

Nelson, R. J., and Trainor, B. C. (2007). Neural mechanisms of aggression. Nat. Rev. Neurosci. 8, 536-546.

Olivier, B. (2004). Serotonin and aggression. Ann. N. Y. Acad. Sci. 1036, 382-392.

Olivier, B., Mos, J., Tulp, M., Schipper, J., Den Daas, S. J., and van Oortmerssen, G.A. (1990). Serotonergic involvment in aggressive behavior in animals. In Violence and Suicidality: Perspectives in Clinical and Psychological Research, H. M. van Praag, R. Plutchik and A. Apter, eds, (Brunner/Mazel, New York), pp. 79-84.

Olivier, B., and van Oorschot, R. (2005). 5-HT1B receptors and aggression: a review. Eur. J. Pharmacol. 526, 207-217.

Oyegbile, T. O., and Marler, C. A. (2006). Weak winner effect in a less aggressive mammal: correlations with corticosterone but not testosterone. Physiol. Behav. 89, 171-179.

Raleigh, M. J., McGuire, M. T., Brammer, G. L., Pollack, D. B., and Yuwiler, A. (1991). Brain Res. 229, 181-190.

Siegel, A. (2004). The Neurobiology of Aggression and Rage. Florida, CRC Press.

Summers, C. H., Korzan, W.J., Lukkes, J. L., Watt, M. J., Forster, G. L., Overli, O., Hoglund, E., Larson, E. T., Ronan, P. J., Matter, J. M., Summers, T. R., Renner, K. J., and Greenberg, N. (2005). Does Serotonin Influence Aggression? Comparing Regional Activity before and during Social Interaction. Physiol. Biochem. Zool. 78, 679-694.

Toth, M., Halasz, J., Mikics, E., Barsy, B., and Haller, J. (2008). Social deprivation from weaning induces disturbed social communication and violent aggression in adulthood. Behav. Neurosci. 122, 849-854.

Tuinier, S., Verhoeven, W. M., and van Praag, H. M. (1995). Cerebrospinal fluid 5-HIAA and aggression: a critical reappraisal of the clinical data. Int. Clin. Psychopharmacol. 10, 147-156.

Van der Vegt, B. J., de Boer, S. F., Buwalda, B., de Ruiter, A. J., de Jong, J. G., and Koolhaas, J.M. (2001). Enhanced sensitivity of postsynaptic serotonin-1A receptors in rats and mice with high trait aggression. Physiol. Behav. 74, 205-211.
Van der Vegt, B. J., Lieuwes, N., Cremers, T. I., de Boer, S. F., and Koolhaas, J. M. (2003a). Cerebrospinal fluid monoamine and metabolite concentrations and aggression in rats. Horm. Behav. 44, 199-208.

Van der Vegt, B. J., Lieuwes, N., van de Wall, E. H., Kato, K., Moya-Albiol, L., Martinez-Sanchis, S., de Boer, S. F., and Koolhaas, J. M. (2003b). Activation of serotonergic neurotransmission during the performance of aggressive behavior in rats. Behav. Neurosci. 117, 667-674.

Van Erp, A. M. ., and Miczek, K. A. (2000). Aggressive behavioe, increased accumbal dopamine and decreased cortical serotonin in rats. J. Neurosci.20, 9320-9325.

Veenema, A. H. (2009). Early life stress, the development of aggression and neuroendocrine and neurobiological correlates: what can we learn from animal models? Front. Neuroendocrinol. 30, 497-518.

Veening, J. G., Coolen, L. M., de Jong, T. R., Joosten, H.W., de Boer, S. F., Koolhaas, J.M., and Olivier, B. (2005). Do similar neural systems subserve aggressive and sexual behaviour in male rats? Insights from c-Fos and pharmacological studies. Eur. J. Pharmacol. 526, 226-239.

Wommack, J.C., Salinas, A., and Delville, Y. (2005). Glucocorticoids and the development of agonistic behaviour during puberty in male golden hamsters. $J$. Neuroendocrinol. 17, 781-787.

Conflict of Interest Statement: The authors declare that the research was conducted in the absence of any commercial or financial relationships that could be construed as a potential conflict of interest.

Received: 25 August 2009; paper pending published: 11 September 2009; accepted: 04 November 2009; published online: 20 November 2009.

Citation: de Boer SF, Caramaschi D, Natarajan D and Koolhaas JM (2009) The vicious cycle towards violence: focus on the negative feedback mechanisms of brain serotonin neurotransmission. Front. Behav. Neurosci. 3:52. doi: 10.3389/neuro.08.052.2009

Copyright (C) 2009 de Boer, Caramaschi, Natarajan and Koolhaas. This is an openaccess article subject to an exclusive license agreement between the authors and the Frontiers Research Foundation, which permits unrestricted use, distribution, and reproduction in any medium, provided the original authors and source are credited. 